\title{
Ün-Duygu-Akıcılık (ÜDA) Modelinde Marka Değerlendirme: GSM Operatörleri Üzerine Bir Çalışma
}

$\ddot{O} \mathbf{z}$

Bu çalışmada ÜDA (Ün- duygu- akıcılık)'nın ardındaki davranışsal iktisat modeli açıklanmakta, GSM operatör sektörü üzerinden vaka çözümü yapılmaktadır. Pazar araştırması ve reklam ajansı System1 Group'un modelinin açıklanması amaçlanmakta olup bu amaç doğrultusunda GSM operatörleri üzerine araştırma yapılmıştır. Ün, markanın pazardaki payını göstermektedir. Duygu, gelecekteki potansiyelini işaret etmektedir. Akıcılık, marka değerini yaratmaktadır. GSM operatörlerin ÜDA modeli çerçevesinde profesyonel çalışanlar üzerinden marka bilinirlikleri nitel araştırma yöntemiyle elde edilen bulgular ışı̆̆ıı da incelenmiştir. ÜDA'da davranışsal iktisatta otomatik karar alma mekanizmasını oluşturan bireyin sistem 1 düşünce sürecindeki tepkisi ölçülmektedir. Modelin amacı kullanıcıyı ikna etmek yerine (sistem 2'ye dayandırmak), kullanıcının algilamasında büyük kolaylı sağlamaktır (sistem l'e hitap etmek). System 1 Group'a göre geleneksel reklam modeli "tüketicilerin sistem 2" düşünce sistemini ikna etme üzerine kuruludur. Ancak, kullanıcıların marka hakkındaki düşünceleri ve hisleri sistem l'e dayanmalıdır. Operatörler arasında seçim yaparken kullanıcının markalardan birini düşünmediği (ün), nötr duygu hissettiği (duygu) ve ayrıştırıcı özellikleri hatırlamadığı (akıcılık) kaydedilmiştir. ÜDA modeli çerçevesinde markalaşmada ve reklam stratejilerinde yapılması gerekenler tartışılmıştır.

Anahtar Kelimeler: Marka, davranışsal iktisat, System1 Group, ÜDA modeli

\section{Fame-Feeling-Fluency (3F) Model on Brand Evaluation: Case Study of GSM Operators}

\begin{abstract}
In this article, behavioral economics models behind $3 F$ (fame-famous-fluency) are explained, and the case from the GSM operator sector is made. According to the marketing research and advertising agency System 1 Group, the elements of a brand are fame, feeling, and fluency $(3 F)$. Fame indicates the brand's market share. Feeling points to the future potential. Fluency creates brand value. Within the framework of the $3 F$ model, brand values of GSM operators are observed in the light of the findings obtained in qualitative technique conducted with professionals. The purpose of the model is not to convince the user (to base it on system 2) but to provide a great convenience in the user's perception (addressing system 1). According to System 1 Group, the traditional advertising model is based on convincing consumers' "system 2" thinking system. However, users' thoughts and feelings about the brand should be based on system 1. It is noted that while a user considers among GSM operators, does not remember (fame), has the neutral emotion feeling (feeling), and does not recall its distinctive features (fluency) about one of the operators based on the system 1 thought process. The suggestions for branding within the framework of the $3 F$ model are discussed.
\end{abstract}

Keywords: Brand, behavioral economics, System 1 Group, $3 F$ model 


\section{Extended Abstract}

In this article, behavioral economics models behind 3F (fame-famous-fluency) designed by System1 Group, are explained, and the case from the GSM operator sector is made.

The selection of the telecommunication sector in the case study is due to the size and competitive environment of the market. While the use of fixed lines has decreased in Turkey, penetration regarding the prevalence of mobile lines has increased from $88 \%$ to $100 \%$ in 2007 . Mobile internet is growing rapidly. Between the same years, it increased from $7 \%$ to $93 \%$. Due to Covid- 19 , remote access and contactless payment have become even more important. In this competitive process, understanding the user comes to the fore. The industry revenue approached 67 billion TL in 2019 from 45.5 billion TL in 2016. As of $2019,41 \%$ of the subscribers are served by Turkcell, $31 \%$ by Vodafone and $28 \%$ by Türk Telekom.

According to the marketing research and advertising agency System1 Group, the elements of a brand are fame, feeling, and fluency (3F). Fame indicates the brand's market share. Feeling points to the future potential. Fluency creates brand value. Within the framework of the $3 \mathrm{~F}$ model, brand values of GSM operators are observed in the light of the findings obtained in qualitative technique conducted with professionals (doctors, economists, lawyers...).

The purpose of the model is not to convince the user (to base it on system 2) but to provide a great convenience in the user's perception (addressing system 1). According to System 1 Group, the traditional advertising model is based on convincing consumers' "system 2" thinking system. However, users' thoughts and feelings about the brand should be based on system 1. System1 Group, in the 3F model, connects the consumer's world in system 1 with the characteristics of the brand. By making the brand familiar by system 1, emotional processing and decision making about it are accelerated.

In the interviews, users were not directly asked about the brand's reputation or sentimentality. The behavior of the user was observed based on the consumption story, the satisfaction or dissatisfaction experienced by the user. In the interviews, users are interviewed based on the customer's experience, not hypothetically.

Our finding shows that three main inferences were obtained in the professional user category:

1. The user remembers the Avea brand only when they think about it (in system 2). It is not on the shortlist in System 1.

2. Avea could not establish an emotional bond with the user. It has neutral feeling.

3. The user can choose the color, logo, etc., which are the fluency of the Avea brand. does not know.

The fact that Avea's "system 1 of the users" has been excluded from the evaluation process indicates that it has lost its brand feature. Avea is not shortlisted. Vodafone is seen by professionals as Turkcell's alternative. Their quality is close to each other. Emotional bonding strength is weak among operators.

In terms of reputation, sound and internet reception are important to the mobile phone consumer. Technology needs to match this.

After equalizing technologically, it should be directed towards nonverbal emotional advertisements. It should add happiness and surprise in its neutral emotional relationship with the user. The publicity should contain an emotional message that corresponds to the consumer and is integrated with the brand.

In terms of fluency, the brand should clearly distinguish itself from others, such as logo and color. The distinctiveness that System1 Group emphasizes is not the product of a design marvel. It is the fact that only one brand is presented in a way that distinguishes it from the others. 


\section{Giriş}

İngiltere merkezli pazar araştırmaları ve reklam ajansı System1 Group'a göre marka, 3F özelliklerine (fame, famous, fluency) sahip olandır: Ün, duygu ve akıcılık (ÜDA) (Kearon vd., 2017: 25-35). Bu araştırmada GSM operatörlerin ÜDA modeli çerçevesinde profesyonel çalışanlar üzerinden marka bilinirlikleri nitel araştırmalarda (mülakatlar) elde edilen bulgular 1şığında incelenmiştir.

Dünya çapında reklam harcamaları 563 milyar ABD dolarıdır (Statista, 2020). Bu kadar büyük harcamaya karşın, firmalar amaçları olan satışlarını ve marka bilinirliklerini artırmaktalar mıdır? System1 Group'a göre, reklamların başarısı üç eşit bölüme ayrılmaktadır: Kaybettiren, başa baş noktada kalan ve kârlı büyümeyi sağlayan reklamlardan oluşmaktadır (Kearon vd., 2017: 1-10). Reklam harcamalarının boşa harcanmasının sebebi, reklamcıların tüketicilerin düşünme süreçlerini ihmal etmeleridir (Damasio, 1994: 50-60). İnsanların davranışsal iktisat, psikoloji ve sosyoloji gibi disiplinler sayesinde tüketicilerin düşünce yapısı çözüldükçe, reklamda kullanılması gereken faktörler formüle edilebilir ve hatırda kalıcı mesajların üretilmesi kolaylaşmaktadır.

System1 Group'un marka algılama modelinin çıkış noktası, tüketicilerin kararlarını davranışsal iktisat çerçevesinde duygusal temelde vermeleridir (Zaltman, 2003: 30-40). System1 Group geliştirdiği ÜDA modeli ile kullanıcı davranışlarını önceden tahmin edildiğini ve reklamın etkinliğinin artırdığını iddia etmektedir (System1, 2020: 1-5). Bunu da etkin reklamların hatırda kalma ve satışların uzun dönemde arttırdığını göstermektedir (Sytem1, 2020). 543 milyar dolarlık dünya reklam bütçesinin $2 / 3$ israf edildiği göz önünde bulundurulursa ufak bir iyileşme oranı bile milyar dolarlara karşılık gelmektedir (System1, 2020: 5-8). Ayrıca etkin reklamın ne olduğu keşfedildikçe reklam harcamaları arttırılacaktır. System1 Group reklam firmasının Londra borsasına açılabilecek büyüklükte olması (SYS1: AIM) göz önüne alındığında modelin analizi ayrıca değer taşımaktadır.

Bu çalışmada ÜDA modelinin teorik açıklaması yapıldıktan sonra, GSM operatörlerinin profesyonel kullanıcılar gözünden marka algıları ortaya konmaktadır. Örnek çalışmada telekomünikasyon sektörünün seçilmesi piyasanın büyüklüğü ve rekabetçi ortamından kaynaklanmaktadır. Türkiye' de sabit hat kullanımı azalırken, mobil hatların yaygınlığına ilişkin penetrasyon 2007'de \%88'den \%100'e ulaşmıştır. Mobil internet hızla artmaktadır. Aynı yıllar arasında, \%7'den \%93'e çıkmıştır. Covid-19 nedeniyle uzaktan erişim ve temassız ödeme daha da önem kazanmıştır. Bu rekabet sürecinde kullanıcıyı anlamak ön plana geçmektedir. Sektör geliri 2016 yılında 45,5 milyar TL'den 2019 yılında 67 milyar TL seviyesine yaklaşmıştır. 2019 itibarıla abonelerin \%41'ine Turkcell, \%31'ine Vodafone, \%28'ine ise Türk Telekom hizmet sağlamaktadır (KPMG, 2020: 1-3). Ancak en yüksek geliri üreten yüksek tarifiyle çalışan profesyonellerin tercihi ciroda ve karda etkin olmaktadır. Bu makalede özellikle bu kesimin ÜDA modeli çerçevesinde tercihi dikkate alınacaktır.

\section{Model ve Literatür}

\section{1. ÜDA Modelinde Tüketicilerin Karar Alma Süreçlerinde Sistem 1 ve Sistem 2 Modelleri}

Kişilerin karar alma süreci beynin otomatik (sistem 1) ve akılcıl (sistem 2) yönlerine dayanarak çalışmaktadır (Kahneman, 2011; 5-25).

Beynin bu ikili yapısı arasında sistem 1 otomatiktir. Uygun bir seçeneği hızlı bir şekilde seçmek ve istenmeyenleri elemek için sezgisel yöntem kullanmaktadır (Gigerenzer, 2008: 723). 11 milyon bitlik hesap gücüne sahiptir (Kearon, 2017). Duygusal tepkilere dayanarak hızlı 
kararlar almak için kısa yollar kullanmaktadır. Sistem 1 basit bir kuralı izler; bu konuda iyi hissedilirse, doğru seçimdir. Kararların büyük çoğunluğu hızlı ve içgüdüseldir (Tversky ve Kahneman, 1974: 1124; Kahneman ve Tversky, 1979: 263; Slovic vd., 2002: 397). Kararlar duygu ve deneyim tarafindan yönlendirilmektedir (Kahneman, 2011: 17-22).

Sistem 2 bilinçli, rasyonel düşünerek sistem 1'e göre daha doğru karar almaktadır. Ama bunun sonucunda daha yavaş bir karar verme sürecinde çalışmaktadır. 50 bitlik bilgisayar düşünme yeteneğine sahiptir (Kearon, 2017).

Sistem 2, sistem 1'e göre çok daha yavaştır ve bu nedenle hızlı bir karar verilmesi gerektiğinde, sistem 1 genellikle baskındır. Kişiler risklerle ve zaman kısıtlamalarıyla karşılaştıklarında, olasılıklara ve matematiksel denklemlere dayanarak karar vermemektedirler. Bunun yerine, kayıp olasılıklarını abartan ve bunu seçimlerinin temeli olarak kullanan zihinsel kısa yol kullanmaktadırlar (Ariely, 2012: 77-90; Thaler ve Sunstein, 2008: 10-14). Öte yandan, sistem 1 mantıksız karar almaya yol açabilecek önyargılara ve hatalara sahiptir (Ariely, 2012: 88-91).

Bütün eksikliklerine rağmen, modern bir tüketici toplumunda, sistem l'e her zamankinden daha fazla ihtiyaç hissedilmektedir. Çünkü satın alma kararının verilmesi gereken binlerce ürün ve hizmet vardır (Kearon vd., 2017). Sistem 1 devreye girmediğinde, vermek zorunda olunan satın alma kararlarının sayısı bilişsel olarak kaldırılamayacak kadar yük oluşturmaktadir.

\subsection{Model: Ün, Duygu ve Akıcılık (ÜDA Modeli)}

System1 Group kendi markasının çıkış ismi sistem 1 düşünme modelinde almaktadır. System1 Group marka analizi çerçevesinde geliştirdiği davranışsal iktisada dayalı modeli ün, duygu ve akıcılıktır. ÜDA modelinde "tüketicinin sistem 1 dünyasındaki" markanın konumu ürünün markalaşıp markalaşmadığını göstermektedir (Wood, 2012: 31).

System1 Group'un iddiasına göre geleneksel reklam modeli "tüketicilerin sistem 2" düşünce sistemini ikna etmesi üzerine kuruludur; ancak kullanıcıların marka hakkındaki düşünceleri ve hisleri Sistem 1'e dayanmalıdır (Wood, 2012: 31).

System1 Group'u, ÜDA modelinde, tüketicinin sistem 1'deki dünyasıyla markanın özellikleri arasında bağ kurmaktadır (Samson ve Voyer, 2012: 48; Bargh, 2002: 280). Markanın sistem 1 tarafından tanıdık hale getirerek, duygusal olarak işlenmesi ve hakkında karar alınmasını hızlandırılmaktadır. Ünün, duygunun ve akıcılığın tüketiciye etkisi ele alınmaktadır.

Ün pazar payı ile ilişkilidir. Ün, markanın bir tüketicinin zihinsel kısa listesine girmesini sağlamaktadır. Tüketici bir markete girdiğinde tek tek raflara bakmamaktadır. Böyle bir uğraş tüketici için çok yorucu olmaktadır. Bunun yerine bir liste yapmakta ve buna göre alışverişini gerçekleştirmektedir. Markanın fonksiyonu bunca ürün yığınları içinde kendini bu kısa listeye aldırmaktır (Kearon vd., 2017: 30-45). Eğer kısa listeye giremediyse, marka özelliğine sahip değildir.

Duygu ürünün gelecekteki büyümesini öngörmektedir (IPA, 2016: 1). Duygu yedi evrensel histen oluşmaktadır: Mutluluk, sürpriz, üzüntü, öfke, korku, iğrenme ve hor görme (Ekman, 2004: 20-30). System 1 Group bu 7 duygu durumuna ek olaraktan herhangi bir tepki verilmeyen nötr halini eklemektedir. Bir reklamın duygusal etkisi, akılda kalmada ve satışta ne kadar etkili olacağına dair en güvenilir kılavuzdur. Ticari anlamda, tüketicinin ürüne, markaya ve reklama karşı duygu eksikliği en kötü durumdur (Kearon vd., 2017: 50-70). 
System 1 Group araştırmalarında, katılımcılardan bir ürün veya bir reklam hakkında ne hissettiklerini belirtmeleri istenmektedir. System1 Group'u, ürünün ve reklamın sahip olduğu duyguyu ölçmektedir. Katılımcılar yedi temel duygudan birini veya tarafsızlığı (nötr duygu) seçmekteler. Yedi evrensel duygudan birini seçerlerse, ne kadar yoğun hissettiklerini ölçmek için takip sorusu sorulmaktadır. System 1 Group'a göre, tüketicilerin seçtikleri olumsuz duygulardan çok, asıl endişelenilmesi gereken tarafsızlık (nötr) duygusudur (Kearon vd., 2017: 50-70). Olumsuz duygular olumluya dönüştürülebilecekken, nötr duygunun dönüşümü güçtür. Örneğin, filmlerde izleyiciyi etkileyen husus olumlu ve olumsuz duyguların beraber verilmesidir. Filmin kahramanının çok iyi haldeyken sonrasında başına birtakım olaylar gelip sarsılması ama en sonunda da bütün bu olumsuzlardan sıyrılması ve tekrar eski haline kavuşması izleyiciyi heyecanlandırmaktadır. Bu durumda her şeyin çok iyi gitmesi bir hikâyeyi sıkıcı hale getirmektedir. Bir reklamın da dozunda olumsuzluk taşıması tüketicinin ilgisinin daha fazla çekilmesini sağlamaktadır.

Akıcılık markaları birbirinden ayrım aracıdır. Akıcılık marka değerini yaratır. Akıcılık, bilgilerin işlenme hızını ve algılamayı kolaylaştırmaktadır (Lee ve Labroo, 2004: 151). Ayırt edicilik kararı hızlandırır (Romaniuk ve Sharp, 2015: 80-90). Bir marka tüketicinin sistem 1'i tarafından kolayca tanınması ve işlenmesi gerekmektedir (Schwarz, 2004: 332; Reber vd., 2004: 364). Ayırt edici logolara, sloganlara, renk şemalarına, cıngıllara sahip markalar akıcılığı kazanmaktadır (Alter ve Oppenheimer, 2008: 985). System 1 Group akıcıllı̆ın ve farklılaşmanın ayrı kavramlar olduğunu vurgulamaktadır. Farklılaşma ün özelliğini destekleyen bir unsur iken akıcılık ise markanın tüketicilerin gözünde ayırt edici varlığıdır. Ayrıca, farklılaşma bazen aksi yönde akıcılığı engellemektedir (Kearon vd. 2017: 27-35). Tüketici farklılaştırılmış inovatif ürünün ne olduğunu anlayamamaktadır. Çünkü bireyin sistem 1'i tarafından algılanamamıştır. Tüketiciler, aşina oldukları ve hızlı bir şekilde işleyebilecekleri markaların ürünlerine yönelmektedir (Dijksterhuis vd., 2004: 56-59).

System1 Group'un bu çerçevede çalışma modeli bir reklam veya bir ürün fikrini ÜDA çerçevesinde test etmesidir. Örneğin son dönemde katkıda bulundukları GSK ilaç firmasının Voltaren ilacı üzerindeki testi duygusallık üzerinden ilerlemiştir. Zira Voltaren ağrı kesici olarak global olaraktan tanınmaktadır. Tüp şekli, jel kıvamı, kutu üzerindeki renkler ve logo yazım şekli tüketici tarafından bilinmektedir. Burada System1 reklam fikri, senaryo ve çekimler esnasında duygu testine tabii tutmuştur. GSK'nın Publicis reklam şirketine yaptırmış olduğu reklamda, System1 Group reklamın kısa aralıklarla izleyicilerde bıraktığı duygusal izlenimi araştırmaktadır. Duygusal olaraktan mutluluk ve sürprizin ağır basmasına göre reklam test edilmektedir. Reklamdaki büyükbaba-torun ilişkisi, hareket etmenin vermiş olduğu mutluluk, eski hareketli günlere dönmenin vermiş olduğu keyif ön plandadır. Yine System1 Group prensibi itibariyle reklam sözsüz iletişime dayalıdır (Walton, 2021: 1).

\subsection{GSM Operatörleri}

GSM operatörler arasındaki rekabet son zamanlarda giderek artmıştır. Operatörlerde bu rekabet ortamından ayakta kalmak için müşteri memnuniyeti ön planda tutmaya çalışmaktalar. Üç operatörün kısa geçmişlerine göz atıldığında, ilk kurulan operatör Turkcell'dir. Turkcell 1993 yılında kurulmuş, faaliyete 1994 yılında geçmiştir. Turkcell 2000 tarihinde Borsa İstanbul'a ve New York Borsası'na açılmıştır (Turkcell.com.tr). İkinci kurulan ve sonradan Vodafone (vodafone.com.tr) tarafından satın alınan Telsim'dir. Üçüncü ve dördüncü operatörleri (Aycell ve Aria) 2004 y1lında birleşmişler, Avea (avea.com.tr) ismiyle hizmetlerini sürdürmüşlerdir.

Operatör tercihleri üzerine çeşitli illerde ve gruplarda araştırma yapılmıştır: 
Üniversite öğrencilerinin operatör tercihini etkileyen unsurlar arasında çekim kalitesi, sosyal çevresi, hesaplı olması ve tanıtım unsurları sayılmaktadır (Gülmez, 2005: 37).

Genç abonelerin operatör seçimlerini etkileyen özellikler üzerine yapılan araştırmada kalite yönüyle Turkcell ve fiyat açısından Avea tercih edilmektedir (Kızgın, 2008: 142).

Kullanıcıların tercihleri üzerinden operatörlerin geliştirme alanları üzerine yapılan çalışmada, Avea'nın, kapsamada, internette, teknolojide ve online işlemler de geliş̧irilmesi önerilmektedir. Turkcell'in paket fiyatında indirime gitmesinin, Vodafone'un ise bayi sayısını artırma ve algılanan imajı ilerletmesinin yerinde olacağı ortaya çıkmıştır (Atmaca ve Keskin, 2014: 60-61).

Yapılan başka bir çalışmada ise GSM operatörleri arasında faturalı/faturasız hat bakımından analiz yapıldığında hizmet kalitesi, ücret, tanıtım, kapsam ve sosyal çevre faktörlerinin anlamlı bir farklılık göstermediği sonucuna ulaşılmıştır (Zanco ve Kaya, 2015: 117).

Şengün ve Menteş (2018: 209) Diyarbakır'da ikamet edenlerin arasında operatör tercihleri araştırmasında dakika ve fiyatın en temel etmenler olduğunu tespit etmişlerdir.

Kıral (2018) Adana'da ikamet edenlerin operatör tercihleri ve geçişkenlik üzerine yaptı̆̆ çalışmada üç operatör arasındaki geçişlerin var olduğunu vurgulamıştır. Uzun vadede Turkcell'in payının düş̧eceğini ve Vodafone'un lider olacağını tahmin etmiştir. Bu çalışmanın Kıral (2018)'e göre farkı, hedef kitle olarak,daha yüksek ciro ve kar etkisine sahip olduğu için sadece profesyonellere odaklanılmıştır (kendi adına çalışan veya kurumsal şirkette karar verici).

Şahin ve Topal (2020: 1155) Kütahya'da ikamet edenlerin cep telefonu operatörü seçmede etkenlerini araştırmışladır. Hizmet, fiyat, reklam, kapsama alanı, sosyal çevre faktörlerinin etkin olduğu görülmüștür.

Beyaz (2013) tarafindan Tokat ilinde yaşayan kullanıcıların GSM operatöründen bekledikleri hizmet kalitesini öğrenmeye yönelik yapılan araştırmada, tüketicilerin kullandıkları GSM operatöründen bekledikleri hizmeti alamadıkları ortaya çıkmıştır. Cinsiyet, meslek, eğitim, gelir GSM operatörü tercihi üzerinde etkili değildir (Beyaz, 2013).

Son yıllardaki çalışmalar ağırlıklı olarak cep telefonuyla kullanıcılar arasında gelişen yoğun ve derinlikli ilişkileri incelemektedirler. Cep telefonu insanların yaşamlarının çok derinine işlemiş durumdadır. Artık bireyin kişilik özellikleri olan (dışa dönüklük-içe dönüklük, deneyime açıklık-tutuculuk gibi) yönleriyle cep telefonu kullanma arasında doğrudan bir ilişki oluşmuştur (Vatandaş, 2020).

Yılmaz (2017) problemli cep telefonunu kullanımını bulmak için ölçek geliştirmiştir. İki gruba ayrılmıştır. Birinci grupta şahsın kişisel ve demografik özellikleri sorulmaktadır. İkinci grupta 22 maddeden bağımlılık, fazla kullanma ve kontrol edememe üzerine sorular yönlendirilmektedir.

Bal ve Balcı'ya göre (2020: 369) cep telefonu bir taraftan insan hayatını kolaylaş̧ııırken, diğer taraftan aşırı kullanım ve bağımlılıkla sonuçlanmaktadır. Üniversite öğrencileri üzerine yaptıkları çalışmada orta derece bağımlılık seviyesi bulmuşlardır. Kullanım süresi artıkça bağımlılık da artmaktadır. Ayrıca kadınların erkeklere göre daha bağımlı olduklarını göstermişlerdir. Bağımlılık seviyesini düşüren kişilik özelliği ise özdenetimliliktir.

Cep telefonu kullanma ve dolayısıyla bağımlılık problemlerinin çıkışı ilk okul çağına inmiş durumdadır. Altay ve Özerbaş'ın (2020:68) yaptıkların araştırmada ilk okul çağındaki öğrencilerin yarısından fazlasının cep telefonu sahibi olduğu, tamamına yakınının cep 
telefonuyla internete bağlanmakta olduğu görülmüştür. Ayrıca ebeveynlerin eğitim seviyeleri arttıkça, problemli cep telefonu kullanma yükselmektedir (Altay ve Özerbaş, 2020: 68).

Rize'de üniversite öğrencileri üzerine yapılan mülakat çalışmasında cep telefonu kullanmanın genç, yerel ve aile arasındaki kültürler arasında bir çatışma aracı ve uygulamalarında kaçış yolu olduğu gözükmektedir (Tunç Subaşı, 2019: 337).

Cep telefonlarıyla bu denli bütünleşik hayat, iletişim dışındaki sektörlerin de ilgisini çekmektedir. Özellikle reklamcılar bunu ürün satışı ve marka yönetim aracı olarak kullanmaya çabalamışlardır. Ancak Doğan ve Duygun (2020) cep telefonu vasitasıyla gönderilen reklamların orta öğretim öğrencilerinin üzerindeki etkisinin zayıf olduğunu ortaya koymuşlardır.

\section{Yöntem}

$\mathrm{Bu}$ çalışmada nitel araştırma yöntemi kullanılmıştır. Değişen algı, tutum ve davranışlardaki temel nedenleri daha iyi açıklayabilmekte öngörülmemiş bilgilere kullanıcıyla mülakat yaparak ulaşma imkânı da sağlamaktadır (Young, 2015: 15). Profesyonellerin operatörü seçerken geçirmiş oldukları deneyimleri derinden anlamak için mülakat yöntemi tercih edilmiştir. $\mathrm{Bu}$ süreçte elde edilen bulguları ÜDA modeli çerçevesinde değerlendirip marka olma nitelikleri açısından GSM operatörler değerlendirilmektedir.

Mülakat yapısı ve amacı olan bir konuşmadır. Kullanıcıların iç seslerinin, niyetlerinin ve amaçlarının ne olduğu sorulmaktadır. Amacı kullanıcılardan hikayeler elde etmektir. Hayatlarını, deneyimlerini ve bakış açılarını anlatmaları istenmektedir (Kumar, 2012: 7-22). Önce kullanıcının çevresi ve hayata bakış açısı anlaşılmaktadır. Somut hikayeler aranmaktadır (Liedtka vd., 2014: 7-13; Akın, 2019a: 24;). Soyut yorum sorusu sorulmamaktadır. Takip soruları derine inmeyi sağlamaktadır. Genel-geçer yüzeysel bilgiler güvenilir değildir. Daha derinlere inildikçe kullanıcının akıl yürütmesi, tepkileri, yol gösterici ilkeleri, motivasyonları öğrenilmektedir. Bunlar güvenilir ve açık yanıtlardır (Akın, 2019b: 2). Kullanıcılara görüşmeler sırasında çözüm sunulmamaktadır. Sadece problemlerinin ortaya çıkartılması amaçlanmaktadır (Young, 2015: 14-17).

Mülakatlarda hem kullanıcıların hem de araştırmacıların zorlandıkları durumlar olabilmektedir. Duygusal ve sosyal deneyimleri kavramak fiziksel deneyimleri kavramaktan daha önemlidir (Liedtka vd., 2014: 54-57). Ürünler, etkinlikler ve ortamlarla ilgili duygusal deneyimler anlaşılmaya çalışılmaktadır. Uzun cevapları içeren sorular sorulmaktadır. Kısa cevap görüşmenin derinlemesine inilmesini engellemektedir. Özellikle kullanıcıların başlarından geçen hikayeler uzun cevap içermelidir (Kumar, 2012: 85).

Katılımcılarla derinlemesine mülakat yapılır. Kullanıcıların hikayelerinden kalıplar ortaya çıkıncaya kadar mülakat serisine devam edilir. Anket çalışmaları korelasyon vermekte ve yüzeysel kalmaktadır (Christensen vd., 2016: 67). Derinlemesine mülakatta kişinin davranışlarının ardındaki sebep-sonuç ilişkileri yakalanmaktadır. Davranışın ardındaki sosyal, duygusal, bilişsel ve kültürel sebepler ortaya konmaktadır. (Nielsen, 2020:1; Faulkner, 2003: 382). Burada esas olan, kullanıcıların deneyimlerinden bir trend çıkıncaya kadar derinlemesine mülakatlara devam etmektir.

Araştırmanın evreni Türkiye'nin her yerinde yaygın olarak bulunan cep telefonu kullanıc1ları arasında 7 adet profesyonel meslek sahipleri -kodlar1- (1 doktor -dok-, 1 bankac1 ban-, 1 finansçı -fin-, 1 girişimci -gir-, 1 bilgisayar mühendisi -bil-, 1 akademisyen -aka-, 1 işletmeci -işle-) arasında geçiş yapmış veya düşünmüş bireylerden oluşmuştur. Bu kesim ekonomik olarak güçlü olmaları sebebiyle hem kendileri hem de organizasyonları için yüksek 
tarifeyi seçebilirler. Bu açından operatörler için ciro, karlılık ve tarife dışı hizmetleri açısından çok önemlidir. Mülakatlar 10 Haziran-10 Temmuz 2019 yılında yapılmıştır.

Örneklemi oluştururken katılımcıların geçiş hikayesi olanlardan seçilmiştir. Motivasyonlarına odaklanılmıştır. Karar alma süreçleri anlaşılmaya çalışılmıştır. Somut hikayesini anlatmasını kolaylaştırmak için, mülakat olan kişilere mevcut GSM markaları üzerinden sorular hazırlanırken, diğer markaları karşılaştırmaları istenmiştir. Böylece, yaşadığı somut deneyim kullanıcının hafızasından dökülmüş̧tür. Marka isimleri sadece hafızasındaki anısını anlatmasını kolaylaştırmak için kullanılmıştır. Temel amaç ÜDA çerçevesinde deneyimlerini toplamaktır.

Görüşmede varsayımsal soru sorulmamaktadır (Tablo-1). Katılımcıların gerçekleştirdiği veya düşündüğü operatörler arasındaki geçiş sorulmaktadır. Neden böyle düşündüğü üzerine sebepleri anlatması beklenmektedir. Varsayımsal olarak, "eğer geçiş yapmayı planlasaydın hangisini seçerdin?" şeklindeki sorulardan kaçınılmaktadır. Bunun nedeni gerçekte kullanıcının refleksinin nasıl olunacağının bilinmemesidir.

Yarı yapılandırılmış mülakat tercih edilmiştir (Harrell ve Melissa, 2009: 56; O'Keeffe vd., 2016: 1911). Mülakat soruları hazırlanmış ve kullanıcının cevaplarına göre ilerlenmiştir (Tablo-1). Örneğin kullanıcılara markaların kullandıkları reklamlar üzerinden soru hazırlanmazken, kullanıcı bu konuyu açtığında (sürpriz şekilde), bunun üzerinden sorular sorulmuştur. Burada yakalanılması gereken anahtar öğe reklam içeriğinin ve reklam oyuncularının performansı değil kullanıcıda oluşturduğu bilişsel ve duygusal deneyimdir.

Tablo 1. Operatör Mülakat Protokolü

Protokol başlangıcı

Ün- Operatörler

Duygular

Akıcılık"
Merhaba, adım .... Cep telefonu operatörlerinin tercihini anlamak için buradayım. Mülakat boyunca, duruma aşina olmayan birine anlatıyormuş gibi davranmanı istiyorum. Senden öğrenmek için geldim.

Avea, Turkcell ve Vodafone'da yaşadığın memnuniyet ve memnuniyetsizliği anlatır mısın?

Daha önce operatörler arasında geçiş yaptın mı? Anlatır mısın? Düşündün mü? Anlatır mısın?

Neden Avea kullanmiyorsun?

Neden Turkcell kullanmiyorsun?

Neden Vodafone kullanmiyorsun?

Yasadığın memnuniyet veya memnuniyetsizlik durumunu hangi duyguyla tanımlarsın? Niçin?

(mutluluk, sürpriz, üzüntü, öfke, korku, iğrenme, hor görme ve tarafsızlık)

Kullandığın operatörün logo, rengi, dükkân vs. özelliklerini anlatır mısın? oldu mu?

Sormam gereken ama sormadığımı bir soru 


\section{Bulgular}

\subsection{Avea/Turk Telekom Markasına Kayıtsız}

Avea, kullanıcıların seçim listesinde sıralamada değildir (ün). Kullanıcılar Turktelekom ile Avea arasındaki ilişkinin farkında değildir. Avea'nın sahipliği konusunda kafalar karışıktır. Turkcell çok etkindir:

-Avea diye bir marka var mı artı? (fin)

-İkisi (Turkcell ve Vodeafone) arasinda fark yok (fin).

-Avea Turk Telekoma mı ait? (ban)

-O (Avea) hala devam ediyor mu? (gir)

-Devlet memurlarının bazıları kullanıyorlar (bil).

-Çevremde diğer operatörleri deneyenler oldu. Hepsi Turkcell'e geri döndüler. Yine de en iyisi Turkcell dediler. Kah faturalar, kah hizmet. Faturasını kaldırabilen öncelikle Turkcell' $i$ tercih ediyor (dok).

-Turkcell kaçınılmaz (işle).

-Turkcell ile Vodafone arasında oynuyorum. Sözleşmem günü ermeye yakın, iki yerden fiyat tekliflerini inceliyorum. Genelde geçiş yapacaklar için avantajl kampanyalar sunuluyor. Geçiş de kolay. Bir telefon bir de bayii ziyaretine baklyor. Babamla arabada bu hafta konuşuyorduk. Vodafone'a mı geçsek diye (Turkcell kullanıyorlar). Fiyat avantajından dolayı (aka).

\section{2. Çekim Kalitesi (Ün)}

Avea'nın çekim kalitesi beğenilmemektedir. Özellikle müzik dinlemek, video seyretmek için kullananlar ile şehirlerarası yolculuk yapanlar Avea'yı tercih etmemektedirler. Turkcell oldukça beğenilmekte ve güvenilir bulunmaktadır.

-Yıllar önce şirket için Turkcell, Vodafone, Avea çekim güçlerine göre karşılaştırdık. Avea en kötü çıtı (gir).

-Müzik dinliyorum. Turkcell interneti kullanıyorum. Turkcell interneti gayet iyi (fin).

-Doktora için şehirlerarası yolculuk yapıyorum. Turkcell şehirlerarası yollarda iyi. Diğerleri zayıf. Çekmiyor. Turkcell kapsama alanında daha iyi (aka).

-Turkcell yarı yolda birakmıyor. Yurt dışında da Turkcell sıkıntısız çalışıyor. Sadece paket almamışsanız pahalı (dok).

-Video seyrediyorum. Turkcell oldukça iyi (işle).

-Turkcell'in çekim kuvvetinden memnunum. İş aralarında, otobüste sık sık kulaklı̆̆ımı takıyorum ve bağlanıyorum (ban).

\subsection{Duygusallık}

\subsubsection{Duygu}

Araştırmada operatörler ile profesyoneller arasındaki duygusal bağın zayıf olduğu görülmüştür. Ancak Avea ile hiçbir duygusal bağ keşfedilememiştir. Avea markası duygusal bağı 
kuramamıştır. Nötrdür. Ancak diğer iki operatör duygusal bağ seviyeleri menfi olmasa da güçlü değildir.

-Avea marka iletişimi zaylf. Bana bir şey ifade etmiyor (fin).

- Turkcell çok ağır basıyor. Marka o kadar her taraftan sarmalıyor ki, hizmeti ve çeşitliliği o kadar rahat ki (işle).

- Isslerini yapsinlar yeterli (dok)

-Bir markaya yönelik bir duygusal bağım olduğunu düşünmüyorum (ban)

-Sanki profesyoneller arasında prestij açısından tercihin Turkcell olduğunu düşünüyorum. En azından iş bağlantısı kurduklarım ya Turkcell ya Vodafone (gir).

\subsubsection{Băğlılık}

Turkcell'in ilk kurulmuş olan operatör olması ve müşteri memnuniyetini muhafaza etmesi bir müşteri bazı yaratmıştır. Bu baz etkisiyle yeni müşteri kazanması veya eski müşterilerini koruması daha muhtemeldir. Bu da kullanıcının alışkanlıklarından dolayı Avea ve Vodafone açısından kullanıcıyı ikna etme sürecini zorlaştırmaktadır: (fin).

-Annem Turkcell numarasını bana devretti. Gençliğimden beri Turkcell kullanıyorum

-Çevredekilerin hepsi Turkcell kullanıyordu. Turkcell kendi aralarında sınırsız veya çok bin dakika veriyor (gir).

-Baştan işim gereği Turkcell ile başladık. Bütün müş̧terilerde bu numaramı biliyor. Böylece de devam ediyoruz (bil).

\subsection{Akıcılık}

\subsubsection{Marka Özellikleri}

Turkcell ve Vodafone'un marka özellikleri bilinirken, Avea'nınki hatırlanmıyor:

-Kırmizı zone'dan taniyorum (fin).

-Turkcell sembolü antenli baş. Sevimli çocuklar (işle).

-Avea'nın sembolünü bilmiyorum (bil).

-Avea görsellikte ve iletişimde bana ulaşamıyor. Vodafone daha iyi ulaşıyor (dok).

-Avea'nın bir cingilı var mı hatırlamıyorum. Ama Turkcell'in şu an bile sizinle konuştuktan sonra çalmaya başladı (ban).

-Kırmizı zon (aka).

-Turkcell'in rengi ve iki başlı anteni gözümün önünde (gir).

\section{Sonuç ve Tartışma}

İnsanlar karar alma mekanizmalarında sistem 1 ve 2'yi kullanmaktalar. Sistem 2 bilişsel düşünceyi ve matematiksel hesaplamaları kapsamaktadır. Bundan dolayı yavaştır. Sistem 1 ise duygusal ve içgüdüseldir. İnsanların çok hızlı olarak beğenisini ifade eder. Düşünme zahmetinden kurtarır. Tüketicilerde bu ürün ve reklam yığınları arasında sistem 1'e güvenerek hareket etmektedirler. 
Mülakatlarda kullanıcılara doğrudan markanın ünü veya duygusallığı sorulmamıştır. Kullanıcının tüketim hikayesinden, yaşadığı memnuniyet veya memnuniyetsizlikten yola çıkarak davranışları gözlenmiştir. Mülakatlarda varsayımsal olarak değil müşterinin deneyimi üzerinden kullanıcılarla görüşülmektedir.

ÜDA modeli çerçevesinde profesyonel meslek sahibi kullanıcı kategorisinde üç ana çıkarım elde edilmiştir:

1. Kullanıcı Avea markasını ancak düşününce (sistem 2'de) hatırlamaktadır. Sistem 1'deki k1sa listesinde değildir.

2. Avea kullanıcıyla duygusal bağ kuramamıştır. Nötr duyguya sahiptir.

3. Kullanıcı Avea markanın akıcılığı olan renk, logo vs. bilmemektedir.

Avea'nın "kullanıcıların sistem 1'lerinin" değerlendirme sürecinden çıkartmaları marka özelliğini yitirdiğini işaret etmektedir. Avea kısa listeye girememektedir. Profesyonellerce Turkcell'in alternatifi Vodafone olarak görülmektedir. Kaliteleri birbirine yakın bulunmaktadır. Duygusal bağ kurma gücü operatörler arasında zayıftır.

Avea'nın tüm ürün, reklam ve promosyonlarında ÜDA'yı geliştirme çerçevesinde etkisini ölçmelidir.

Ün açısından, cep telefonu tüketicisi için ses ve internet çekim gücü önemlidir. Teknolojisinde bunu eşitlemesi gereklidir.

Teknolojik olarak eşitledikten sonra, sözsüz duygusal reklamlara yönlenmelidir (Kearon, 2017). Kullanıcıyla olan nötr duygusal ilişkisinde mutluluk ve sürpriz katmalıdır. Kullanıcı kitlesinin duygusal olarak atfettiği değerlerle kendisi arasında bir ilişki kurmalıdır. Tüketicilerin aklında sözlü reklamların mesajları değil sözsüz reklamların markayı nasıl hissettirdiği kalmaktadır (Kearon vd., 2017). Ancak her duygusal içerik kalıcı olmamaktadır. Tüketicide karşılığı olan ve markayla bütünleşik bir mesaj içermelidir.

Akıcılık özelliklerinde markanın logo, renk gibi net bir şekilde kendisini diğerlerinden ayırt etmelidir. System1 Group'un vurguladığı ayırt edicilik tasarım harikası ürünler değildir. Sadece bir markayı diğerlerinden ayırt edici şekilde sunulmuş olmasıdır (Landwehr, 2016).

Operatörler üzerinde Sistem 1 ve 2 davranışsal iktisat teorisinden yola çıkarak System 1 Group'un ÜDA modeli kısıtlamaları içinde analiz yapılmış ve bu model çerçevesinde değerlendirilmiştir. Her model kendi kurgusunda doğrudur. Örneğin konumlandırma modeli (positioning) üzerinden yürünmüş olsaydı (Ries and Trou, 2001: 10-25), Avea markasının kendi kategorisinde daha üst seviyede yer almasından söz edilebilirdi. Bunun yanında finansal getiri modeli çerçevesinden değerlendirildiğinde ise en güçlü getiri oranlarına sahip olabilirdi. System1 Group çalışmalarında kullanıcıların hangi markayı ve reklamı beğendikleri sorulmaksızın, ÜDA çerçevesinde dolaylı sorularak etkinlikleri araştırılmaktadır. Ayrıca profesyoneller dışında diğer önemli hedefli kitleler arasında operatör tercihleri üzerine analiz farklı sonuçlar çıkartabilir.

Bu model başta tüketici sektörü olmak üzere inovasyon ve hatta siyasi partilerin adayları üzerine uygulanabilir. System1 Group hem girişimcilerle hem de siyasi partilerle çalışmaktadırlar. 


\section{Kaynakça}

Altay, D., ve Özerbaş, M. (2020). İlkokul öğrencilerinin problemli cep telefonu kullanımlarının farklı değişkenler açısından incelenmesi. TÜBAV Bilim Dergisi, 13 (1), 68-84.

Alter, A. L., ve Oppenheimer, D. M. (2008), Easy on the mind, easy on the wallet: The roles of familiarity and processing fluency in valuation judgments. Psychonomic Bulletin \& Review, 15(5), 985-990.

Akın, M.S. (2019a). Kullanıcı gerçekten ne ister? etnografik metotları ile derinlemesine araştırma. Anadolu Ikktisat ve İşletme Dergisi, 3 (1), 1-25

Akın, M.S. (2019b). Kullanıcının bağlamının önemi ve bağlamsal sorgulama. Istanbul Management Journal, 87, 1-25.

Ariely, D. (2012). Predictably Irrational. New York: Harper Perennial.

Atmaca, E, Keskin, M. (2014). Gsm operatörlerine yönelik müşteri memnuniyet araştırması. Çukurova Üniversitesi İktisadi ve İdari Bilimler Fakültesi Dergisi, 18, 1, 45-63.

Bal, E. ve Balcı, Ş. (2020). Akıllı Cep Telefonu Bağımlılığı: Kişilik Özellikleri ve Kullanım Örüntülerinin Etkinliği Üzerine Bir İnceleme. Erciyes İletişim Dergisi, 7 (1), 369-394.

Bargh, J.A. (2002). Losing consciousness: Automatic influences on consumer judgment, behavior, and motivation. Journal of Consumer Research, 29(2), 280-285.

Beyaz, Rafet (2013). GSM operatörlerinin hizmet kalitesi açısından servqual yöntemi kullanılarak değerlendirilmesi: Tokat ilinde uygulama. Gaziosmanpaşa Üniversitesi Üretim Yönetimi ve Pazarlama Anabilim Dalı yayınlanmamış yüksek lisans tezi.

Christensen C. M., Hall, T., Dillon K., ve Duncan D. S. (2016). Know your customers "jobs to be done". Harvard Business Review, September.

Dijksterhuis, A., Smith, P. K., Barwise, P. ve Meehan, S. (2004), Simply better. Boston, MA.: Harvard Business School Press.

Damasio, A. R. (1994). Descartes' error: Emotion, reason, and the human brain. New York, NY: Grosset/Putnam Press.

Doğan, E. ve Duygun, A. (2020). SMS reklamlarına yönelik tutum ve davranışlarda cep telefonu kullanım amaçlarının rolü: ortaöğretim öğrencileri üzerine bir araştırma. Местиа, (9), 153-173.

Ekman, P. (2004). Emotions revealed: Understanding faces and feelings. London, UK: Phoenix.

Faulkner, L. (2003). Beyond the five-user assumption: Benefits of increased sample sizes in usability testing. Behavior Research Methods, Instruments, \& Computers, 35, 379-383.

Gigerenzer, G. (2008). Gut feelings: Short cuts to better decision making. London, UK: Penguin Books.

Gülmez, M. (2005). Üniversite öğrencilerinin cep telefonu satın alma ve kullanımını etkileyen faktörler: Sivas Cumhuriyet Üniversitesi ile Tokat Gaziosmanpaşa Üniversitelerinde bir uygulama. Erciyes Üniversitesi İktisadi ve İdari Bilimler Fakültesi Dergisi, 24, 37-62

Harrell, Margaret C., ve Melissa A. Bradley. (2009). Data Collection Methods: Semi-Structured Interviews and Focus Groups. California: The RAND Corporation.

IPA (2016). Advertising works 23: tpa effectiveness awards 2016. London: WARC.

Kahneman, D. (2011). Thinking, fast and slow. London, UK: Allen Lane.

Kahneman, D., ve Tversky, A. (1979). Prospect theory: An analysis of decisionunder risk. Econometrica, 47, 263-291.

Kearon, J., Wood, O., ve Ewing, T. (2017). System 1 unlocking profitable growth. System1 Group PLC. London: U.K.

Kearon, J. (2017). We think much less than we think we think AANA presents RESET 2017. https://www.youtube.com/watch?v=mzQ_bGVVbzw Erişim tarihi: 5.04.2020. 
Kıral, E. (2018). Markov analizi ile cep telefonu operatör tercihlerinin belirlenmesi: Adana ili üzerine bir uygulama, Çukurova Üniversitesi Sosyal Bilimler Enstitüsü Dergisi, 27 (1), $35-47$.

Kızgın, Y. (2008). Genç gsm abonelerinin operatör seçimlerini etkileyen değişkenlerin konumlandırılması üzerine bir alan araştırması: Muğla Üniversitesi öğrencileri örneği. Yönetim ve Ekonomi Araştırmaları Dergisi, 6 (10), 142-161.

KPMG (2020). Telekom bakış. https://assets.kpmg/content/dam/kpmg/tr/pdf/2020/05/sektorel-bakis-2020telekomunikasyon.pdf

Kumar, V. (2012). 101 Design methods: a structured approach for driving innovation in your organization. Wiley, Chicago.

Landwehr, J. R. (2016). Processing fluency of product design: Cognitive and affective routes to aesthetic preferences. In R. Batra, C. Seifert, ve D. Brei (Eds.), The psychology of design: Creating consumer appeal (pp.218-233). New York, NY: Routledge.

Lee, A. Y., ve Labroo, A. A. (2004). The effect of conceptual and perceptual fluency on brand evaluation. Journal of Marketing Research, 41, 151-165.

Liedtka, J., Ogilvie, T., ve Brozenske, R. (2014). The Designing for growth field book: a stepby-step project guide. Columbia Business School Publishing, New York.

Nielsen, J. (2020). How many test users in a usability study? https://www.nngroup.com/articles/howmany-test-users/

O'Keeffe, Jimmy, Wouter Buytaert, Ana Mijic, Nicholas Brozovic, and Rajiv Sinha. (2016). The use of semi-structured interviews for the characterisation of farmer irrigation practices. Hydrology and Earth System Sciences, 20: 1911-1924.

Reber, R., Schwarz, N., ve Winkielman, P. (2004). Processing fluency and aesthetic pleasure: Is beauty in the perceiver's processing experience? Personality and Social Psychology Review, 8, 364-382.

Ries A. ve Trout, J. (2001). Positioning: the battle for your mind. McGraw Hill Professional

Romaniuk, J., ve Sharp, B. (2015). How brands grow: Part 2. Melbourne, Australia: Oxford University Press.

Schwarz, N. (2004). Metacognitive experiences in consumer judgment and decision making. Journal of Consumer Psychology, 14, 332-348.

Slovic, P., Finucane, M. L., Peters, E., ve MacGregor, D. G. (2002). The affect heuristic. In T. Gilovich, D. Griffin, ve D. Kahneman (Eds.), Heuristics and biases: The psychology of intuitive judgment (pp. 397-420). New York, NY: Cambridge University Press.

Samson, A., ve Voyer, B. (2012). Two minds, three ways: Dual system and process models in consumer psychology. AMS Review, 2, 48-71.

Statista (2020). Global advertising spending from 2010 to 2019https://www.statista.com/statistics/236943/global-advertising-spending/ Erişim tarihi: 10.03 .2019

System 1 Group (2020). 10 things we learned from super bowl. https://system1 group.com/resources/latest-articles Erişim tarihi: 8.04.2020.

Şahin, H, Topal, B. (2020). Cep Telefonu Kullanıcılarının GSM Operatörü Tercihine Etki Eden Faktörlerin Araştırılması: Kütahya İli Örneği. Düzce Üniversitesi Bilim ve Teknoloji Dergisi, 8 (1), 1155-1172.

Şengün, H, Menteş, N. (2018). GSM operatör markalarının tüketici açısından değerlendirilmesi. Mukaddime, 9 (1), 209-230.

Thaler, R. H. and Sunstein. C. R. (2008). Nudge: Improving decisions about health, wealth, and happiness. Yale University Press.

Tunç Subaşı, S. (2019). Telefonda takılmak: boş zaman, hegemonya ve gençlik kültürü . Moment Dergi, Media and Participation, 337-353 . 
Tversky, A., ve Kahneman, D. (1974). Judgment under uncertainty: Heuristics and biases. Science (New Series), 185, 1124-1131.

Vatandaş, S. (2020). Gençlerin Kişilik Özellikleri Bağlamında Cep Telefonunun Anlam ve Önemi. Avrasya Sosyal ve Ekonomi Araştırmaları Dergisi, 7 (4), 208-226.

Walten, B. (2021). Case Study: GSK Voltaren All Gain. No Pain.

https://system1 group.com/case-study/gsk-voltaren-case-study / Erişim tarihi: 16.11.2021.

Wood, O. (2012). How emotional tugs trump rational pushes: The time has come to abandon a 100-year-old advertising model. Journal of Advertising Research, 52(1), 31-39.

Yılmaz, B. (2017). Ortaokul öğrencilerinin problemli cep telefonu kullanımlarının farklı değişkenler açısından incelenmesi. Ankara Üniversitesi Ĕ̆itim Bilimleri Enstitüsü, Ankara, 13(7), 109-128.

Young, I. (2015). Practical empathy: For collaboration and ceativity in your work. New York: Rosenfeld Media.

Zaltman, G. (2003). How customers think: essential insights into the mind of the markets, Harvard Business School Press, Boston.

Zanco, F ve Kaya, A. (2015). Üniversite öğrencilerinin gsm operatörü tercih nedenlerinin araştırılması: bir uygulama. The International New Issues in Social Sciences , 1 (1) , 117 142. 